\title{
Erratum to: Reprogramming EF-hands for design of catalytically amplified lanthanide sensors
}

Korrie L. Mack • Olesia V. Moroz •

Yurii S. Moroz • Alissa B. Olsen •

Jaclyn M. McLaughlin • Ivan V. Korendovych

Published online: 25 April 2013

(c) SBIC 2013

Erratum to: J Biol Inorg Chem (2013) 18:411-418

DOI 10.1007/s00775-013-0985-5

In the original publication of the article, the equation for fitting chemical denaturation included an error (Page 413). The corrected equation is given below.

$$
\begin{aligned}
M R E= & \frac{M R E_{f}+M R E_{u 1} e^{-\frac{\Delta G_{1}-m_{1}[D]}{R T}}}{1+e^{-\frac{\Delta G_{1}-m_{1}[D]}{R T}}} \\
& +\frac{M R E_{f 1}+M R E_{u} e^{-\frac{\Delta G_{2}-m_{2}[D]}{R T}}}{1+e^{-\frac{\Delta G_{2}-m_{2}[D]}{R T}}}
\end{aligned}
$$

The chemical denaturation data in the published article were fit to the correct equation given above.

The online version of the original article can be found under doi:10.1007/s00775-013-0985-5.

K. L. Mack · O. V. Moroz · Y. S. Moroz - A. B. Olsen ·

J. M. McLaughlin · I. V. Korendovych ( $\square)$

Department of Chemistry, Syracuse University,

Syracuse, NY 13244, USA

e-mail: ikorendo@syr.edu 